\title{
Video-assisted thoracoscopic surgery and thoracotomy during lobectomy for clinical stage I non-small-cell lung cancer have equivalent oncological outcomes: A single-center experience of 212 consecutive resections
}

\author{
CHUNHUA LIU ${ }^{1}$, ZHONGDONG LI $^{2}$, CUIQING BAI ${ }^{3}$, LI WANG ${ }^{1}$, XUEFEI SHI $^{1}$ and YONG SONG \\ Departments of ${ }^{1}$ Respiratory Medicine and ${ }^{2}$ Cardiothoracic Surgery, Jinling Hospital, Nanjing University \\ School of Medicine, Nanjing, Jiangsu 210002; ${ }^{3}$ Department of Respiratory Medicine, \\ Nanfang Hospital, Southern Medical University, Guangzhou, Guangdong 510515, P.R. China
}

Received January 4, 2014; Accepted August 22, 2014

DOI: $10.3892 / \mathrm{ol} .2014 .2804$

\begin{abstract}
The aim of the present study was to compare the oncological outcomes following lobectomy using either video-assisted thoracoscopic surgery (VATS) or thoracotomy in clinical stage I non-small cell lung cancer (NSCLC) patients. Short- and long-term data from 212 consecutive patients who underwent lobectomy for clinical stage I NSCLC via VATS or thoracotomy between February 2003 and July 2013 were retrospectively reviewed. The primary endpoints were mediastinal lymph node staging, disease-free survival time and overall survival time. A total of 212 lobectomies for clinical stage I NSCLC were performed, 123 by VATS and 89 by thoracotomy. Patients' demographic data, pathological stage and residual tumor were similar in the two groups. Reduced blood loss, less post-operative analgesia required and earlier hospital discharge were recorded for the VATS group, as compared with the thoracotomy group. The overall morbidity was similar in the two groups. However, the rate of major complications was higher following thoracotomy than following VATS. No 30-day mortality occurred subsequent to either thoracotomy or VATS lobectomy. The overall survival and disease-free survival times were comparable between the two groups. In the univariate analysis, the treatment approach was not associated with the overall five-year survival or the disease-free survival times. Multivariate Cox regression analysis of survival times revealed that significant predictors of shorter survival times were advanced pathological T3 stage, pathological $\mathrm{N} 1$ or $\mathrm{N} 2$ disease and poor cancer differentiation. In conclusion,
\end{abstract}

Correspondence to: Professor Yong Song, Department of Respiratory Medicine, Jinling Hospital, Nanjing University School of Medicine, 305 East Zhongshan Road, Nanjing, Jiangsu 210002, P.R. China

E-mail: yong_song6310@yahoo.com

Key words: video-assisted thoracoscopic surgery, thoracotomy, non-small cell lung cancer, mediastinal lymph node, disease-free survival, overall survival it is reasonable to conclude from the present study that VATS lobectomy performed by specialist thoracic surgeons is safe and may achieve similar long-term survival times to the open surgery approach. However, further prospective randomized multi-center trials are warranted prior to incorporating VATS into clinical routine.

\section{Introduction}

Lung cancer remains the leading cause of cancer morbidity and mortality worldwide $(1,2)$. Lobectomy by thoracotomy is recognized as a primary procedure in the treatment of early-stage non-small cell lung cancer (NSCLC) (3-6). Although lobectomy via thoracotomy provides optimal locoregional control and long-term survival, this procedure is associated with high mortality and morbidity rates: 2-10 and $30-50 \%$, respectively (2-6). Therefore, the identification of alternative techniques that diminish surgical trauma without compromising oncological outcome is required. Jacobaeus first performed thoracoscopy for inspecting the pleural space in 1910 (7). Until the 1980s, thoracoscopy was only employed for diagnosis of pleural diseases. However, after McKenna reported his initial experiences of 44 patients who had undergone video-assisted thoracoscopic surgery (VATS) in 1994 (8), major advances in VATS, such as VATS lobectomy and VATS segmentectomy, were achieved in the late 1990s (9). With the worldwide employment of VATS, reduced postoperative trauma and postoperative morbidity has been reported (10-12). Certain surgeons employ VATS lobectomy to reduce surgical trauma. However, the oncological outcomes following VATS lobectomy, as measured using mediastinal lymph node dissection and long-term survival times, have not been fully elucidated (9,13-19). In addition, few multi-center randomized controlled trials that compare the two approaches and the long-term oncological outcomes have been conducted (16-19).

VATS lobectomy for clinical stage I NSCLC was introduced to Jingling Hospital (Nanjing, China) in January 2008. The thoracic surgeons in the Department of Thoracic Surgery of the hospital have the basic ability to perform VATS. The present 
study aimed to assess the oncological outcomes following VATS lobectomy by reviewing five years of experience performing VATS lobectomy at the hospital.

\section{Patients and methods}

Patient evaluation. The present retrospective study complied with the Declaration of Helsinki rules and was approved by the Ethics Committee of Jinling Hospital (Nanjing, China). The requirement for informed consent from all patients was waived due to the retrospective nature of the study.

Data from 212 consecutive patients with clinical stage I NSCLC who underwent lobectomy at the Department of Thoracic Surgery, Nanjing General Hospital of Nanjing Military Command (Nanjing, China) between February 2003 and July 2013 were retrospectively reviewed. All patients underwent bronchoscopy, endobronchial ultrasound, and computed tomographic scans of the brain, chest and upper abdomen prior to surgery. Mediastinoscopy was not required except when positive mediastinal or hilar lymph nodes were detected using the chest computed tomographic scan. Positron emission tomography-computerized tomography $(\mathrm{CT})$ and bone scanning were performed on all patients. Classification of the tumor clinical stage was determined by the 7th edition of the TNM classification of lung cancer (20), which was proposed by the Union for International Cancer Control (UICC) and the International Association for the Study of Lung Cancer (IASLC). The mediastinal lymph node staging was determined by the most recent lymph node map proposed by the IASLC (21). For those patients who underwent surgery prior to 2009 , staging was recalculated to match the 7th edition of TNM classification of lung cancer proposed by UICC and IASLC (21).

Surgical technique. All surgical procedures, including VATS and thoracotomy, were performed by three senior surgeons with proven expertise in lung cancer, who had conducted $>60$ VATS lobectomies and $>300$ open lobectomies prior to the present study. The selection of VATS or open lobectomy was decided by the patients and their families. The resection was considered to be administered with curative intent (R0) in all cases. Only trocars and endsocopic instruments were used in the VATS lobectomies and no rib spreading was performed. All patients underwent one-lung ventilation and were placed in the lateral decubitus position. Mediastinal lymph node dissection was routinely performed. We did not perform an intra-operative lymph node frozen section analysis, due to the time-consuming nature of the procedure.

On the left side, the 5, 6, 7, 8, 9, 10, 11 and 12 lymph node stations, and on the right side, the $2 \mathrm{R}, 4 \mathrm{R}, 7,8,9,10,11$ and 12 lymph node stations were systematically dissected en bloc. The lymph nodes were dissected with the integrity of the surrounding structure, with clear recognition of the anatomical landmarks and with no nodal structures. Lymph node stations 10, 11 and 12, and the affected lobes were systematically dissected. On the right side, when the mediastinal pleura were opened, stations $2 \mathrm{R}$ and $4 \mathrm{R}$ was dissected up to the lowest visible section of the subclavian artery. After the lung was retracted anteriorly, station 7 dissection was performed. Regardless of middle lobectomy and lower lobectomy, stations 8 and 9 were systematically harvested. On the left side, stations 5 and 6 were systematically harvested. Subsequently, dissection of stations 7, 8 and 9 was performed (16).

Surgical outcome and post-operative complications. The operative time, degree of blood loss, pathological stage, overall number of lymph nodes dissected, residual tumor status, post-operative morbidity occurring within 30 postoperative days and length of hospital stay were assessed. The morbidity occurring within 30 postoperative days, which included major and minor complications, was graded according to the Clavien-Dindo classification (22). Major complications were defined as grades 3b, 4a, 4b and 5. Minor complications were classified as grades 1, 2 and 3a. The 30-day mortality was defined as all-cause fatality within 30 postoperative days.

Follow-up. During the first year following treatment, the patients were assessed every three months at the outpatient department. In the second year, follow-up was conducted every six months and, subsequently, follow-up was performed at the end of each year. During follow-up, diagnostic investigations were performed. All patients received CT chest scans prior to discharge and prior to each follow-up visit. Any post-operative complications and medical conditions that required hospitalization were reviewed. The final follow-up assessment occurred in November 2013.

Statistical analysis. For statistical analysis, SPSS 13.0 for Windows (SPSS, Inc., Chicago, IL, USA) was used. Data are presented as the mean \pm standard deviations for variables following a normal distribution, and were analyzed by Student's t-test. For variables following a non-normal distribution, the results are expressed as the median and range, and were compared by nonparametric test. Differences of semi-quantitative results were analyzed by the Mann-Whitney $\mathrm{U}$ test. Differences of qualitative results were analyzed by the $\chi^{2}$ or Fisher exact test, where appropriate. The survival rates were analyzed using the Kaplan-Meier method; the differences between the two groups were analyzed with the log-rank test. The overall survival time was classified as the time period between the date of surgery and the date of the final follow-up or fatality from any cause. The disease-free survival time was calculated as the time period between the date of surgery and the date of cancer recurrence or fatality from any cause. Univariate analysis was performed to identify prognostic variables associated with overall survival time. Univariate variables with $\mathrm{P}<0.05$ were selected for inclusion in the multivariate Cox proportional-hazards regression model. The adjusted odds ratios along with the corresponding 95\% confidence intervals were calculated. $\mathrm{P}<0.05$ was considered to indicate a statistically significant difference.

\section{Results}

Demographic data. The demographic data are summarized in Table I. During the present study, 123 lobectomies by VATS and 89 lobectomies by thoracotomy were performed. No significant differences were identified in age, gender, comorbidity, forced expiratory volume in the first second (observed to predicted), tumor size, clinical stage, number of mediastinoscopies and American Society of Anesthesiologists Physical 
Table I. Demographic data.

\begin{tabular}{|c|c|c|c|}
\hline Parameter & $\operatorname{VATS}(n=123)$ & Thoracotomy $(\mathrm{n}=89)$ & P-value \\
\hline Age, years ${ }^{\mathrm{a}}$ & $65.0(50-70)$ & $64.0(46-75)$ & 0.859 \\
\hline Gender, male:female & $74: 49$ & $51: 38$ & 0.676 \\
\hline Comorbidity, $\mathrm{n}$ & & & 0.373 \\
\hline COPD & 2 & 1 & \\
\hline Hypertension & 12 & 8 & \\
\hline Diabetes Mellitus & 6 & 2 & \\
\hline Smoking & 46 & 32 & \\
\hline Atrial fibrillation & 1 & 2 & \\
\hline Earlier myocardial infarction & 1 & 2 & \\
\hline FEV1 (observed to predicted), $\%^{\mathrm{b}}$ & $86.0(76-95)$ & $86.0(80-98)$ & 0.920 \\
\hline Tumor size, $\mathrm{cm}^{\mathrm{b}}$ & $1.90(0.8-3.9)$ & $1.90(0.5-3.9)$ & 0.675 \\
\hline Clinical stage, $\mathrm{n}$ & & & 0.750 \\
\hline IA & 65 & 49 & \\
\hline IB & 58 & 40 & \\
\hline Mediastinoscopy, n & 2 & 3 & 0.713 \\
\hline ASA score, $n$ & & & 0.546 \\
\hline $\mathrm{I}$ & 66 & 42 & \\
\hline II & 59 & 45 & \\
\hline III & 1 & 2 & \\
\hline
\end{tabular}

${ }^{\mathrm{a}}$ Median (range) and ${ }^{\mathrm{b}}$ mean ( \pm SD). VATS, video-assisted thoracoscopic surgery; COPD, chronic obstructive pulmonary disease; FEV1, forced expiratory volume in the first second; ASA, American Society of Anesthesiologists.

Status classification system score (23) between the two groups $(\mathrm{P}>0.05)$.

Surgical outcome and pathological data. The surgical and pathological outcomes are summarized in Table II. No conversion to open lobectomy occurred in the cases where VATS was performed. No intraoperative or in-hospital mortality occurred in either group. Significantly longer operative times were recorded in the VATS group as compared with the open surgery group $(\mathrm{P}<0.05)$. No significant differences in pathological stage or residual tumor status between the two groups was identified $(\mathrm{P}>0.05)$. Patients in the VATS group exhibited significantly faster recovery, with reduced blood loss $(\mathrm{P}<0.05)$, less post-operative analgesia required $(\mathrm{P}<0.05)$ and earlier hospital discharge $(\mathrm{P}<0.05)$ than the patients who had undergone thoracotomy.

Lymph nodes and stations harvested. The nodes and stations harvested, including N1 and N2, are summarized in Table III. No significant differences between the two groups were detected when comparing either the number of lymph node stations or the overall number of lymph nodes dissected $(\mathrm{P}>0.05)$ The numbers of harvested lymph nodes and lymph node stations were also similar in the two groups $(\mathrm{P}>0.05)$. The number of harvested lymph nodes in each resection was $>10$ and a minimum of six lymph node stations from each patient were harvested. The lymphadenectomy results were comparable with those of other studies (Table IV).
Post-operative complications. The post-operative complications in the VATS and thoracotomy groups are reviewed in Table V. The overall morbidity within 30 postoperative days was similar in the two groups $(\mathrm{P}>0.05)$. However, when the severity of complications was compared, a significantly greater number of complications were classified as major in patients who had undergone thoracotomy, as compared with the VATS patients $(\mathrm{P}<0.05)$.

Overall survival. The median follow-up duration was 36 months, with similar average follow-up times in the two groups. No differences in overall survival times between the VATS and open surgery groups were identified ( $\mathrm{P}=0.624$; Fig. 1). The three- and five-year overall survival rates were 79.2 and $71.6 \%$, respectively, in the VATS group as compared with 72.6 and $68.0 \%$, respectively, in the thoracotomy group. Multivariate Cox regression analysis of the overall survival times of all patients in the whole cohort was also performed. Significant predictors of shorter overall survival times were T3 pathological stage $(\mathrm{P}=0.001)$, pathological $\mathrm{N} 1$ or $\mathrm{N} 2$ disease $(\mathrm{P}=0.001)$, and poor tumor differentiation $(\mathrm{P}=0.005)$ (Table VI). The VATS surgical approach was not found to be a significant predictor for overall survival time by univariate analysis.

Disease-free survival. When the disease-free survival rates were examined, the three- and five-year disease-free survival rates were 75.3 and $59.0 \%$, respectively, in the VATS group as compared with 70.1 and $58.2 \%$, respectively, in the thoracotomy 
Table II. Surgical and pathological data.

\begin{tabular}{|c|c|c|c|}
\hline Clinical parameter & VATS $(n=123)$ & Thoracotomy $(\mathrm{n}=89)$ & P-value \\
\hline Type of resection, $\mathrm{n}$ & & & 0.305 \\
\hline Left upper lobectomy & 36 & 16 & \\
\hline Left lower lobectomy & 24 & 20 & \\
\hline Right upper lobectomy & 21 & 13 & \\
\hline Right middle lobectomy & 10 & 8 & \\
\hline Right lower lobectomy & 32 & 32 & \\
\hline Operative time, $\min ^{\mathrm{a}}$ & $200.0(120-380)$ & $160.0(100-330)$ & 0.000 \\
\hline Blood loss, $\mathrm{ml}^{\mathrm{a}}$ & $160.0(100-320)$ & $210.0(110-500)$ & 0.000 \\
\hline Histological type, $n$ & & & 0.166 \\
\hline Adenocarcinoma & 101 & 81 & \\
\hline Squamous cell carcinoma & 20 & 7 & \\
\hline Other & 2 & 1 & \\
\hline Pathological stage, $\mathrm{n}$ & & & 1.000 \\
\hline IA & 42 & 26 & \\
\hline IB & 64 & 51 & \\
\hline IIA & 10 & 7 & \\
\hline IIB & 5 & 3 & \\
\hline IIIA & 2 & 2 & \\
\hline Residual tumor, R0/R1/R2, n & $122 / 1 / 0$ & $87 / 2 / 0$ & 0.384 \\
\hline Post-operative analgesia, days ${ }^{\mathrm{b}}$ & $2.0(1.0-5.0)$ & $5.0(1.0-6.0)$ & 0.000 \\
\hline Duration of chest drainage, days ${ }^{b}$ & $6.0(3-9)$ & $7.0(5-13)$ & 0.000 \\
\hline Hospital stay, days ${ }^{\mathrm{b}}$ & $8.0(6-21)$ & $16.0(11-21)$ & 0.000 \\
\hline
\end{tabular}

${ }^{\mathrm{a}}$ Median (range) and ${ }^{\mathrm{b}}$ mean $( \pm \mathrm{SD})$. VATS, video-assisted thoracoscopic surgery; COPD, chronic obstructive pulmonary disease; FEV1, forced expiratory volume in the first second; ASA, American Society of Anesthesiologists.

Table III. Nodes and stations harvested.

\begin{tabular}{|c|c|c|c|}
\hline Parameter $^{\mathrm{a}}$ & $\operatorname{VATS}(\mathrm{n}=123)$ & Thoracotomy $(\mathrm{n}=89)$ & P-value \\
\hline No. of harvested lymph node stations & $8.0(6-8)$ & $8.0(6-8)$ & 0.449 \\
\hline No. of mediastinal lymph node stations dissected & $5.0(3-5)$ & $5.0(3-5)$ & 0.344 \\
\hline No. of harvested lymph nodes & $28.0(22-36)$ & $28.0(22-40)$ & 0.164 \\
\hline No. of mediastinal lymph nodes dissected & $17.0(12-23)$ & $17.0(12-28)$ & 0.110 \\
\hline
\end{tabular}

${ }^{a}$ Median (range). VATS, video-assisted thoracoscopic surgery.

group, with no statistically significant differences identified between the two groups ( $\mathrm{P}=0.988$; Fig. 1$)$. To determine whether the patients who underwent VATS exhibited a higher incidence of recurrent cancer as compared with the open surgery patients, recurrence patterns and time to recurrence were examined (Table VII). The location of the recurrence and the time to recurrence were not significantly different between the two groups. No port-site recurrence was noted in the VATS cases. Multivariate Cox regression analysis of disease-free survival times revealed that significant predictors of shorter disease-free survival times were advanced pathological T3 stage $(\mathrm{P}=0.023)$, pathological N1 or $\mathrm{N} 2$ disease $(\mathrm{P}=0.003)$ and poor tumor differentiation $(\mathrm{P}=0.020)$ (Table VIII). The surgical approach was not found to be a significant predictor for reduced disease-free survival times. The oncological outcomes were comparable with those of other large sample size studies (Table IX).

\section{Discussion}

Although VATS lobectomy for stage I NSCLC has been widely used due to proven benefits, the merits of the technique with regard to oncological outcomes remains controversial (24-27). 
Table IV. Literature review of mediastinal lymph node dissection using VATS vs. thoracotomy.

\begin{tabular}{|c|c|c|c|c|c|}
\hline Study & No. patients & $\begin{array}{l}\text { Lymph } \\
\text { nodes }\end{array}$ & $\begin{array}{l}\text { N1 lymph } \\
\text { nodes }\end{array}$ & $\begin{array}{l}\text { N2 lymph } \\
\text { nodes }\end{array}$ & $\begin{array}{c}\text { Lymph node } \\
\text { stations }\end{array}$ \\
\hline Palade et al (18) & VATS: 32 & 25.1 & 10.5 & NR & NR \\
\hline (2013, Germany) & Open: 32 & 25.2 & 8.9 & & \\
\hline Yang et al (16) & VATS: 31 & 28.2 & 9.5 & 18.6 & 6.8 \\
\hline (2013, China) & Open: 31 & 29.8 & 8.4 & 21.4 & 6.7 \\
\hline Ramos et al (15) & VATS: 96 & 22.6 & NR & 17.7 & 5.1 \\
\hline (2012, France) & Open: 200 & 25.4 & & 18.2 & 4.5 \\
\hline Watanabe et al (17) & VATS: 191 & 33.8 & NR & 23.4 & NR \\
\hline (2005, Japan) & Open: 159 & 30.9 & & 21.0 & \\
\hline
\end{tabular}

Lymph node data are presented as the means. VATS, video-assisted thoracoscopic surgery; NR, not reported.

Table V. Post-operative complications.

\begin{tabular}{|c|c|c|c|}
\hline Adverse event & VATS $(n=123)$ & Thoracotomy $(n=89)$ & P-value \\
\hline Post-operative complications, $\mathrm{n}$ & 31 & 21 & 0.763 \\
\hline Severity of complications, $n$ & & & 0.002 \\
\hline Major $(3 b, 4 a, 4 b$ or 5$)$ & 4 & 11 & \\
\hline $\operatorname{Minor}(1,2$ or $3 a)$ & 27 & 10 & \\
\hline Major, $\mathrm{n}$ & & & 1.000 \\
\hline Pulmonary embolism & 1 & 3 & \\
\hline Acute coronary syndrome & 1 & 2 & \\
\hline Respiratory insufficiency & 1 & 4 & \\
\hline $\mathrm{DIC}$ & 1 & 2 & \\
\hline Minor, $\mathrm{n}$ & & & 1.000 \\
\hline Pneumonia & 6 & 2 & \\
\hline Wound infection & 3 & 1 & \\
\hline Urinary tract infection & 4 & 1 & \\
\hline Atrial fibrillation & 5 & 1 & \\
\hline Chylothorax & 3 & 1 & \\
\hline Recurrent nerve palsy & 3 & 1 & \\
\hline Prolonged air leak (>5 days) & 3 & 3 & \\
\hline Mortality within 30 days after surgery, $n$ & 0 & 0 & \\
\hline
\end{tabular}

Lymph node data are presented as the means. VATS, video-assisted thoracoscopic surgery; NR, not reported.

According to the Society of Thoracic Surgeons database (28), only $20 \%$ of lobectomies are performed via VATS, with $80 \%$ conducted using conventional thoracotomy. The success of VATS can only be definitively measured using the long-term survival times, as compared with those following thoracotomy. In the present study, VATS lobectomy and thoracotomy lobectomy were compared using a consecutive series of patients who underwent surgery performed by surgeons extensively experienced in VATS and open lobectomies. The study demonstrated that VATS lobectomy achieves similar oncological results to conventional thoracotomy.
Although previous studies have been conducted regarding the effect of mediastinal lymph node removal and systematic mediastinal lymph node dissection on long-term survival times $(29,30)$, there remains controversy with regard to the impact of lymphadenectomy on oncological outcome (31). The largest prospective randomized control trial comparing mediastinal lymph node sampling with dissection, termed the Z0030 trial, was reported by the American College of Surgery Oncology Group (29). This trial revealed that mediastinal lymph node dissection achieved similar long-term survival times as compared with lymph node sampling in early-stage NSCLC 
Table VI. Multivariate Cox regression analysis of overall survival times.

\begin{tabular}{|c|c|c|c|}
\hline Regression variable & Adjusted hazard ratio & $95 \% \mathrm{CI}$ & P-value \\
\hline \multicolumn{4}{|l|}{ Pathological T stage } \\
\hline $\mathrm{T} 1$ & 1.00 & & \\
\hline $\mathrm{T} 2$ & 1.23 & $0.51-2.36$ & $0.896^{\mathrm{a}}$ \\
\hline $\mathrm{T} 3$ & 2.36 & $1.52-5.69$ & $0.001^{\mathrm{a}}$ \\
\hline \multicolumn{4}{|l|}{ Pathological N stage } \\
\hline No & 1.00 & & \\
\hline $\mathrm{N} 1 / \mathrm{N} 2$ & 1.23 & $0.65-3.65$ & $0.001^{\mathrm{b}}$ \\
\hline \multicolumn{4}{|l|}{ Differentiation grade } \\
\hline Good & 1.00 & & \\
\hline Moderate & 1.36 & $0.36-2.36$ & $0.259^{c}$ \\
\hline Poor & 3.25 & $1.23-6.89$ & $0.005^{\mathrm{c}}$ \\
\hline
\end{tabular}

${ }^{\mathrm{a} C}$ Compared with T1; ${ }^{\mathrm{c}}$ compared with N0; ${ }^{\mathrm{c}}$ compared with differential grade 'good'.

A

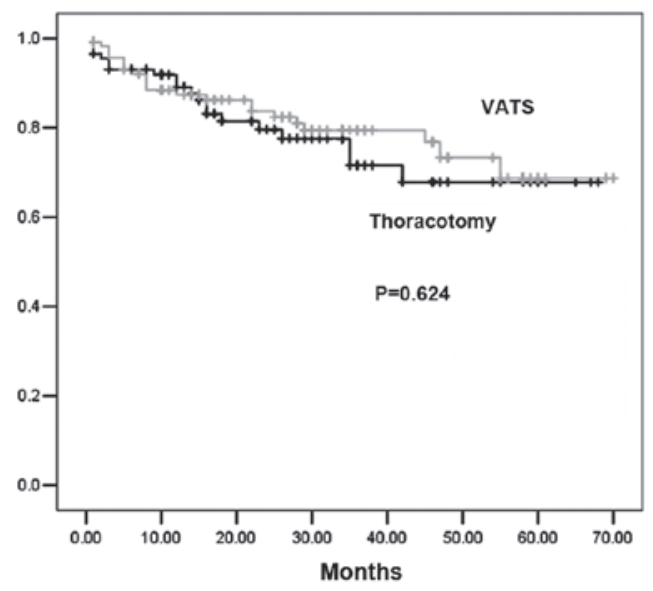

B

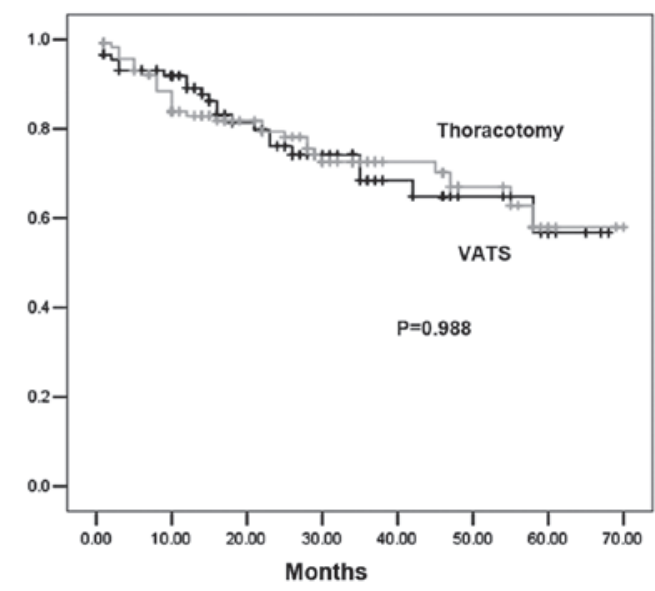

Figure 1. (A) Overall survival and (B) disease-free survival in association with lobectomy approach (VATS vs. thoracotomy) in 212 consecutive patients. VATS, video-assisted thoracoscopic surgery.

patients without evidence of mediastinal or hilar lymph node metastasis confirmed by sampling. Therefore, the result of the Z0030 trial is only suitable for highly selected NSCLC patients and is not applicable for all operable NSCLC patients. Since producing intra-operative frozen sections is time-consuming and the results of the Z0030 trial are only applicable for particular patients, intra-operative lymph node staging is not performed in China. However, in a prospective randomized control trial involving 532 patients with clinical stage I-IIIA NSCLC, 268 patients underwent mediastinal lymph node dissection and 264 patients underwent mediastinal lymph node sampling performed by Chinese surgeons (30). The five-year survival rate in the patients who had undergone mediastinal lymph node dissection was significantly higher than that in those who had mediastinal lymph node sampling performed $(\mathrm{P}<0.05)$, regardless of the clinical stage. Thus, systematic mediastinal lymph node dissection was routinely performed for all operable NSCLC patients in the present study cohort.
The quality of mediastinal lymph node dissection is the core component when VATS lobectomy is performed. The majority of studies previously reported have revealed no differences in the quality of mediastinal lymph node dissection during VATS as compared with thoracotomy (16-19). However, certain studies have reported the quality of lymph node dissection to be inferior to that of thoracotomy, particularly in the early stages of VATS lobectomy (31-33). The CALGB 39802 study (32), a prospective multi-center study, observed that over half of the resections in patients undergoing VATS had fewer than two stations sampled and $\sim 15 \%$ resections in patients undergoing VATS had no lymph nodes harvested. The quality of lymphadenectomy in the CALGB 39802 study was far from the recommendation proposed by IASLC that a minimum of six lymph node stations be removed or sampled in lobectomy $(31,34)$. IASLC also recommends that three of these lymph node stations be mediastinal lymph nodes $(31,34)$. The results from the present study revealed that the number of 
Table VII. Comparison of recurrence pattern and site following lobectomy.

\begin{tabular}{|c|c|c|c|}
\hline Recurrence parameter & VATS & Thoracotomy & P-value \\
\hline Overall recurrence, $\mathrm{n}(\%)$ & $15(12.1)$ & $12(13.5)$ & 1.000 \\
\hline Locoregional, n (\%) & $8(6.5)$ & $7(7.9)$ & 1.000 \\
\hline Mediastinal lymph node & 2 & 1 & \\
\hline Pleura & 2 & 3 & \\
\hline Ipsilateral lung & 4 & 3 & \\
\hline Distant, n (\%) & $7(5.6)$ & $5(5.6)$ & 1.000 \\
\hline Brain & 3 & 2 & \\
\hline Liver & 2 & 2 & \\
\hline Bone & 1 & 1 & \\
\hline Median time to recurrence, months & 18 & 16 & 0.360 \\
\hline
\end{tabular}

VATS, video-assisted thoracoscopic surgery.

Table VIII. Multivariate Cox regression analysis of disease-free survival times.

\begin{tabular}{lccc}
\hline Regression variable & Adjusted hazard ratio & 95\% CI & \\
\hline Pathological T stage & & & \\
T1 & 1.00 & $0.63-2.69$ & 0.450 \\
T2 & 1.36 & $1.56-4.62$ & 0.023 \\
T3 & 3.20 & & \\
Pathological N stage & & $0.96-4.21$ & \\
N0 & 1.00 & & \\
N1/N2 & 2.31 & 0.003 \\
Differentiation grade & & $0.25-3.22$ \\
Good & 1.00 & $1.69-6.32$ \\
Moderate & 1.62 & \\
Poor & 3.58 & 0.230 \\
\hline
\end{tabular}

dissected lymph node stations and lymph nodes were similar in VATS and thoracotomy, and that the quality of lymphadenectomy was applied with recommendation proposed by IASLC.

An increasing number of studies have reported similar perioperative outcomes following VATS and open lobectomy $(32,35)$. The results from the present study did not differ from the conclusions drawn from other studies; VATS lobectomy was safe and less trauma occurs, as compared with thoracotomy (16-19). In the present study, the NSCLC patients who underwent VATS lobectomy benefited from a quicker recovery, with less bleeding, reduced post-operative pain, shorter duration of chest drainage and earlier hospital discharge as compared with the patients who underwent thoracotomy lobectomy, and these findings were comparable with those of previous studies $(36,37)$.

The long-term outcomes, measured by overall survival and disease-free survival times, were comparable with those of other studies concerning VATS versus open lobectomy (24-27,37). As thoracic surgeons became more skillful with VATS and recognized the benefits, such as shorter recovery times and reduced trauma, establishing prospective randomized multi-center trials that compared VATS and thoracotomy was difficult, due to difficulty in enrolling patients on a long-term basis, as VATS have a short-term outcome when compared with open resection. Studies regarding the long-term outcomes of VATS versus open lobectomy are mainly retrospective and produce prospective non-randomized comparisons (24-27,36). These studies have revealed marginally improved overall survival and disease-free survival times following VATS (24-27,37). In the present study, the patients who had undergone VATS exhibited marginally improved survival times and later recurrence than the patients who had thoracotomy performed. This finding may be difficult to explain. Chen et al (38) have hypothesized that the reduced trauma during VATS lobectomy may result in quicker recovery time, earlier administration of adjuvant chemotherapy and improved compliance with adjuvant chemotherapy. The other factor may be that the reduced immunological suppression during VATS as compared with thoracotomy increases the patient's ability to scavenge residual cancer cells shed into the blood or lymphatics at 
Table IX. Literature review of long-term survival rates following VATS or thoracotomy.

\begin{tabular}{|c|c|c|c|c|c|c|c|}
\hline \multirow[b]{2}{*}{ Study } & \multirow[b]{2}{*}{ Clinical stage } & \multirow[b]{2}{*}{ Approach } & \multirow[b]{2}{*}{ No. } & \multicolumn{2}{|c|}{$\begin{array}{c}\text { Overall } \\
\text { survival rate }(\%)\end{array}$} & \multicolumn{2}{|c|}{$\begin{array}{c}\text { Disease-free } \\
\text { survival rate }(\%)\end{array}$} \\
\hline & & & & Three-year & Five-year & Three-year & Five-year \\
\hline Lee et al (23) & $\mathrm{I}$ & VATS & 188 & 87.4 & 76.5 & 77.7 & 61.1 \\
\hline (2013, USA) & & Open & 187 & 81.6 & 77.5 & 76.9 & 72.1 \\
\hline Thomas et al (24) & I & VATS & 110 & NR & 62.9 & NR & NR \\
\hline (2002, France) & & Open & 404 & NR & 62.8 & NR & NR \\
\hline Shiraishi et al (25) & I & VATS & 81 & NR & 89.1 & NR & 79.0 \\
\hline (2006, Japan) & & Open & 79 & NR & 77.7 & NR & 80.2 \\
\hline Flores et al (26) & I & VATS & 398 & NR & 79.0 & NR & NR \\
\hline$(2009, \mathrm{USA})$ & & Open & 343 & NR & 75.0 & NR & NR \\
\hline
\end{tabular}

VATS, video-assisted thoracoscopic surgery; NR, not reported.

lobectomy (36,38-40). However, the underlying mechanisms for this process require further investigation.

Certain limitations of the present study must be acknowledged. The study was based at a single center, not at multiple centers, and the results were produced from retrospective analysis, not prospective randomized analysis. Therefore, bias in the selection of patients and the surgical approach, by the surgeons, cannot be excluded. This limitation needs accounting for when interpreting the results. Other factors that may affect long-term outcomes and prognosis, such as adjuvant therapy and treatment for recurrence and distant metastasis, are not completely described by this analysis.

In summary, it is reasonable to conclude from the present study that VATS lobectomy performed by specialist thoracic surgeons is safe and achieves similar long-term survival times to the open surgery approach. However, further prospective randomized multi-center trials are warranted prior to the incorporation of VATS into clinical routine practice.

\section{Acknowledgements}

The authors would like to thank the patients, their families and hospital colleagues involved in this study. The study was supported by the Natural Science Foundation of Jiangsu Province (grant no. BK2011658).

\section{References}

1. Jacobaeus HC: Ueber die Moglichkeit die Zystoskopie bei Untersuchung seroser Hohlungen anzuwenden. Munchner Meditinische Wochenschrift 57: 2090-2092, 1910.

2. Siegel R, Naishadham D and Jemal A: Cancer statistics, 2013. CA Cancer J Clin 63: 11-30, 2013.

3. She J, Yang P, Hong Q and Bai C: Lung cancer in China: challenges and interventions. Chest 143: 1117-1126, 2013.

4. Ettinger DS, Akerley W, Borghaei H, et al; National comprehensive cancer network: Non-Small Cell Lung Cancer, Version 2.2013. J Natl Compr Canc Netw 11: 645-653, 2013.

5. Lächelt S, Alber M, Söhn M, et al: Intensity-modulated stereotactic radiotherapy for the treatment of medically inoperable patients with NSCLC stage I. Oncol Rep 28: 1309-1314, 2012.
6. Zhang J, Qi J, Chen N, et al: High expression of a disintegrin and metalloproteinase-9 predicts a shortened survival time in completely resected stage I non-small cell lung cancer. Oncol Lett 5: 1461-1466, 2013

7. Song PP, Zhang W, Zhang B, Liu Q and Du J: Effects of different sequences of pulmonary artery and vein ligations during pulmonary lobectomy on blood micrometastasis of non-small cell lung cancer. Oncol Lett 5: 463-468, 2013.

8. McKenna RJ Jr: Lobectomy by video-assisted thoracic surgery with mediastinal node sampling for lung cancer. J Thorac Cardiovasc Surg 107: 879-881, discussion 881-882, 1994.

9. Li Z, Liu H and Li L: Video-assisted thoracoscopic surgery versus open lobectomy for stage I lung cancer: A meta-analysis of long-term outcomes. Exp Ther Med 3: 886-892, 2012.

10. Li W, Wang Y, He X, et al: Combination of CT-guided hookwire localization and video-assisted thoracoscopic surgery for pulmonary nodular lesions: Analysis of 103 patients. Oncol Lett 4: 824-828, 2012.

11. Yang CF and D'Amico TA: Thoracoscopic segmentectomy for lung cancer. Ann Thorac Surg 94: 668-681, 2012.

12. Zhong C, Fang W, Mao T, et al: Comparison of thoracoscopic segmentectomy and thoracoscopic lobectomy for small-sized stage IA lung cancer. Ann Thorac Surg 94: 362-367, 2012.

13. Lee HS and Jang HJ: Thoracoscopic mediastinal lymph node dissection for lung cancer. Semin Thorac Cardiovasc Surg 24: 131-141, 2012.

14. Li G: Minimally invasive thoracic surgery: news from the 3rd Asian-Pacific VATS Performance \& the 6th China Lung Cancer MITS Forum. J Thorac Dis 4: 681-687, 2012.

15. Ramos R, Masuet C and Gossot D: Lobectomy for early-stage lung carcinoma: a cost analysis of full thoracoscopy versus posterolateral thoracotomy. Surg Endosc 26: 431-437, 2012.

16. Ramos R, Girard P, Masuet C, Validire P and Gossot D: Mediastinal lymph node dissection in early-stage non-small cell lung cancer: totally thoracoscopic vs thoracotomy. Eur J Cardiothorac Surg 41: 1342-1348, 2012.

17. Yang H, Li XD, Lai RC, et al: Complete mediastinal lymph node dissection in video-assisted thoracoscopic lobectomy versus lobectomy by thoracotomy. Thorac Cardiovasc Surg 61: 116-123, 2013.

18. Watanabe A, Koyanagi T, Ohsawa H, et al: Systematic node dissection by VATS is not inferior to that through an open thoracotomy: a comparative clinicopathologic retrospective study. Surgery 138: 510-517, 2005

19. Palade E, Passlick B, Osei-Agyemang T, Günter J and Wiesemann S: Video-assisted vs open mediastinal lymphadenectomy for Stage I non-small-cell lung cancer: results of a prospective randomized trial. Eur J Cardiothorac Surg 44: 244-249, 2013

20. Reck M,Heigener DF, Mok T, Soria JC and Rabe KF: Management of non-small-cell lung cancer: recent developments. Lancet 382: 709-719, 2013. 
21. Rusch VW, Asamura H, Watanabe H, et al: Members of IASLC Staging Committee: The IASLC lung cancer staging project: a proposal for a new international lymph node map in the forthcoming seventh edition of the TNM classification for lung cancer. J Thorac Oncol 4: 568-577, 2009.

22. Clavien PA, Barkun J, de Oliveira ML, et al: The Clavien-Dindo classification of surgical complications: five-year experience. Ann Surg 250: 187-196, 2009.

23. Froehner M, Koch R, Litz R, Heller A, Oehlschlaeger S and Wirth MP: Comparison of the American Society of Anesthesiologists Physical Status classification with the Charlson score as predictors of survival after radical prostatectomy. Urology 62: 698-701, 2003.

24. Lee PC, Nasar A, Port JL, et al: Long-term survival after lobectomy for non-small cell lung cancer by video-assisted thoracic surgery versus thoracotomy. Ann Thorac Surg 96: 951-961, 2013.

25. Thomas P, Doddoli C, Yena S, et al: VATS is an adequate oncological operation for stage I non-small cell lung cancer. Eur J Cardiothorac Surg 21: 1094-1099, 2002.

26. Shiraishi T, Shirakusa T, Hiratsuka M, Yamamoto $S$ and Iwasaki A: Video-assisted thoracoscopic surgery lobectomy for c-T1N0M0 primary lung cancer: its impact on locoregional control. Ann Thorac Surg 82: 1021-1026, 2006.

27. Flores RM, Park BJ, Dycoco J, et al: Lobectomy by video-assisted thoracic surgery (VATS) versus thoracotomy for lung cancer. J Thorac Cardiovasc Surg 138: 11-18, 2009.

28. Ceppa DP, Kosinski AS, Berry MF, Tong BC, Harpole DH, Mitchell JD, D'Amico TA and Onaitis MW: Thoracoscopic lobectomy has increasing benefit in patients with poor pulmonary function: a Society of Thoracic Surgeons Database analysis. Ann Surg 256: 487-493, 2012.

29. Scott WJ, Allen MS, Darling G, et al: Video-assisted thoracic surgery versus open lobectomy for lung cancer: a secondary analysis of data from the American College of Surgeons Oncology Group Z0030 randomized clinical trial. J Thorac Cardiovasc Surg 139: 976-983, 2010.
30. Wu Yl, Huang ZF, Wang SY, Yang XN and Ou W: A randomized trial of systematic nodal dissection in resectable non-small cell lung cancer. Lung Cancer 36: 1-6, 2002.

31. D'Andrilli A, Venuta F and Rendina EA: The role of lymphadenectomy in lung cancer surgery. Thorac Surg Clin 22: 227-237, 2012.

32. Swanson SJ, Herndon JE II, D'Amico TA, et al: Video-assisted thoracic surgery lobectomy: report of CALGB 39802 - a prospective, multi-institution feasibility study. J Clin Oncol 25: 4993-4997, 2007.

33. Okada M, Sakamoto T, Yuki T, et al: Hybrid surgical approach of video-assisted minithoracotomy for lung cancer: significance of direct visualization on quality of surgery. Chest 128: 2696-2701, 2005.

34. Verhagen AF, Schoenmakers MC, Barendregt W, et al: Completeness of lung cancer surgery: is mediastinal dissection common practice? Eur J Cardiothorac Surg 41: 834-838, 2012.

35. Chin CS and Swanson SJ: Video-assisted thoracic surgery lobectomy: centers of excellence or excellence of centers? Thorac Surg Clin 18: 263-268, 2008.

36. Murthy S: Video-assisted thoracoscopic surgery for the treatment of lung cancer. Cleve Clin J Med 79: eS23-eS25, 2012.

37. Papiashvilli M, Stav D, Cyjon A, et al: Lobectomy for non-small cell lung cancer: differences in morbidity and mortality between thoracotomy and thoracoscopy. Innovations (Phila) 7: 15-22, 2012.

38. Chen FF, Zhang D, Wang YL and Xiong B: Video-assisted thoracoscopic surgery lobectomy versus open lobectomy in patients with clinical stage I non-small cell lung cancer: a meta-analysis. Eur J Surg Oncol 39: 957-963, 2013.

39. Gorenstein LA and Sonett JR: The surgical management of stage I and stage II lung cancer. Surg Oncol Clin N Am 2011 20: 701-720, 2011.

40. Puri V and Meyers BF: Video-assisted thoracoscopic surgery lobectomy for lung cancer. Surg Oncol Clin N Am 22: 27-38, 2013. 